\title{
The Opioid Epidemic and Primary Headache Disorders: A Nationwide Population-Based Study
}

Urvish K. Patel ${ }^{1}$, Preeti Malik ${ }^{2,3}$, Dhaivat Shah ${ }^{4}$, Ashish Sharma ${ }^{5}$, Jatminderpal Bhela ${ }^{6}$, Bindi Chauhan ${ }^{7}$ , Deepkumar Patel ${ }^{8}$, Nashmia Khan ${ }^{9}$, Ashish Kapoor ${ }^{10}$, Tapan Kavi ${ }^{11}$

1. Neurology and Public Health, Icahn School of Medicine at Mount Sinai, New York, USA 2. Public Health, Icahn School of Medicine at Mount Sinai, New York, USA 3. Pediatrics, The Children's Hospital at Montefiore, Bronx, USA 4. Clinical Research, Icahn School of Medicine at Mount Sinai, New York, USA 5. Internal Medicine, Yuma Regional Medical Center, Yuma, USA 6. Psychiatry, MetroHealth System, Case Western Reserve University School of Medicine, Cleveland, USA 7. Public Health, Long Island University, New York, USA 8. Public Health, School of Health Sciences and Practice, New York Medical College, Valhalla, USA 9. Internal Medicine, MultiCare Tacoma General Hospital, Tacoma, USA 10. Neurology, Bayonne Medical Center - CarePoint Health \& Jersey City Medical Center - RWJBarnabas Health, Jersey City, USA 11. Neurology, Cooper Neurological Institute, Cooper University Hospital, Camden, USA

Corresponding author: Urvish K. Patel, dr.urvish.patel@gmail.com

\section{Abstract}

\section{Introduction}

The opioid epidemic has been linked to several other health problems, but its impact on headache disorders has not been well studied. We performed a population-based study looking at the prevalence of opioid use in headache disorders and its impact on outcomes compared to non-abusers with headaches.

\section{Methodology}

We performed a cross-sectional analysis of the Nationwide Inpatient Sample (years 2008-2014) in adults hospitalized for primary headache disorders (migraine, tension-type headache [TTH], and cluster headache $[\mathrm{CH}])$ using the International Classification of Diseases, Ninth Revision, Clinical Modification (ICD-9-CM) codes. We performed weighted analyses using the chi-square test, Student's t-test, and Cochran-Armitage trend test. Multivariate survey logistic regression analysis with weighted algorithm modelling was performed to evaluate morbidity, disability, and discharge disposition. Among US hospitalizations during 2013-2014, regression analysis was performed to evaluate the odds of having opioid abuse among headache disorders.

\section{Results}

A total of 5,627,936 headache hospitalizations were present between 2008 and 2014 of which 3,098,542 (55.06\%), 113,332 (2.01\%), 26,572 (0.47\%) were related to migraine, TTH, and $\mathrm{CH}$, respectively. Of these headache hospitalizations, $128,383(2.28 \%)$ patients had abused opioids. There was a significant increase in the prevalence trend of opioid abuse among patients with headache disorders from 2008 to 2014. The prevalence of migraine (63.54\% vs. $54.86 \%$ ), TTH (2.29\% vs. $2.01 \%)$, and CH ( $0.59 \%$ vs. $0.47 \%$ ) was also higher among opioid abusers than non-abusers ( $\mathrm{p}<0.0001)$. Opioid abusers with headaches were more likely to be younger ( 43 years old vs. 50 years old), men ( $30.17 \%$ vs. $24.78 \%$ ), white ( $80.83 \%$ vs. $73.29 \%$ ), Medicaid recipients (30.15\% vs. $17.03 \%$ ), and emergency admissions ( $85.4 \%$ vs. $78.51 \%$ ) as compared to opioid nonabusers with headaches $(\mathrm{p}<0.0001)$. Opioid abusers with headaches had higher prevalence and odds of morbidity (4.06\% vs. 3.70\%; adjusted odds ratio [aOR]: 1.48 ; $95 \%$ CI: $1.39-1.59$ ), severe disability (28.14\% vs. 22.43\%; aOR: 1.58; 95\% CI: 1.53-1.63), and discharge to non-home location (17.13\% vs. $18.41 \%$; aOR: 1.35 ; 95\% CI: 1.30-1.40) as compared to non-abusers. US hospitalizations in years 2013-2014 showed the migraine (OR: 1.61; 95\% CI: 1.57-1.66), TTH (OR: 1.43; 95\% CI: 1.22-1.66), and CH (OR: 1.34; 95\% CI: 1.01-1.78) were linked with opioid abuse.

\section{Conclusion}

Through this study, we found that the prevalence of migraine, TTH, and CH was higher in opioid abusers than non-abusers. Opioid abusers with primary headache disorders had higher odds of morbidity, severe disability, and discharge to non-home location as compared to non-abusers.

Categories: Neurology, Public Health, Epidemiology/Public Health

Keywords: opioid, opioid epidemic, headache, migraine, cluster headache, tension headache, primary headache disorder, nationwide inpatient sample

\section{Introduction}

Headache disorder is one of the leading conditions for emergency department visit, accounting for $0.5 \%$ to $2.8 \%$ of all visits $[1,2]$. Headaches are also the third highest cause worldwide of years lost due to disability [3]. 
Migraine, tension-type headache (TTH), and cluster headache $(\mathrm{CH})$ are the most common types of primary headache. Prolonged personal suffering, impaired quality of life, and economic burden are commonly associated with chronic headache disorders [4].

Opioids are often prescribed more than any other non-steroidal anti-inflammatory drugs as a primary level of therapy for headache [5]. Prolonged use of an opioid in patients with headache disorders, such as migraine, carries a high risk of medication overuse headache. According to the American Headache Society, prolonged and overuse of opioids (more than 10 times per month) can lead to medication overuse headaches and cause occasional migraines to transition to chronic migraine [6]. The opioid epidemic has affected a number of other disorders; however, its impact on headache disorders has not been well studied. The relationship is especially important as opioids are an important treatment modality for headache disorders.

Hence, we conducted this study to determine the trend of opioid abuse among patients with primary headache disorders, evaluate whether opioid-dependent and non-dependent opioid abuse associated with headache disorders, and its relationship with outcomes like morbidity, disability, and discharge disposition.

\section{Materials And Methods}

Data was obtained from the Agency for Healthcare Research and Quality's Healthcare Cost and Utilization Project (HCUP) Nationwide Inpatient Sample (NIS) between January 2008 and December 2014. The NIS is the largest publicly available all-payer inpatient care database in the United States and contains discharge-level data provided by states that participate in the HCUP (including a total of 46 in 2011). This administrative dataset contains data on approximately eight million hospitalizations in 1,000 hospitals that were chosen to approximate a $20 \%$ stratified sample of all US community hospitals, representing more than $95 \%$ of the national population. Criteria used for stratified sampling of hospitals into the NIS include hospital ownership, patient volume, teaching status, urban or rural location, and geographic region. Discharge weights are provided for each patient discharge record, which allows extrapolation to obtain national estimates. Each hospitalization is treated as an individual entry in the database and is coded with one principal diagnosis, up to 24 secondary diagnoses, and 15 procedural diagnoses associated with that stay. Detailed information on NIS is available at http://www.hcup-us.ahrq.gov/db/nation/nis/nisdde.jsp. The NIS is a de-identified database, so informed consent or Institutional Review Board approval was not needed for the study. The HCUP Data Use Agreement (HCUP-348L73IZS) for the data utilized in this study was obtained.

\section{Study population}

We used the International Classification of Diseases, Ninth Revision, Clinical Modification (ICD-9-CM) codes to identify adult patients admitted to hospital with a primary diagnosis of migraine, TTH, and CH (ICD-9-CM code Migraine: 346, TTH: 339.1 or 307.81, and CH: 339.0). Similarly, patients with opioid dependence and non-dependent opioid abuse were identified using ICD-9-CM code 304.0 and 305.5, respectively. Age $<18$ years and admissions with missing data for age, gender, and race were excluded. The sample size was based on the available data. Data from NIS has previously been used to identify and analyze the trends, outcomes, healthcare costs, and disparities of care $[7,8]$. We have not considered available NIS data from the years 2015 and 2016 due to the lack of literature showing the validity of ICD-10 for identifying headache disorders.

\section{Patient and hospital characteristics}

Patient characteristics of interest were age, gender, race, insurance status, and concomitant diagnoses as defined above. Race was defined by white (referent), African American, Hispanic, Asian or Pacific Islander, and Native American. Insurance status was defined by Medicare (referent), Medicaid, private insurance, and other/self-pay/no charge. We defined the severity of comorbid conditions using Deyo's modification of the Charlson comorbidity index (CCI) (Table 1). 


\section{Cureus}

\begin{tabular}{|c|c|c|}
\hline Condition & ICD-9-CM codes & Charlson score \\
\hline Myocardial infarction & 410-410.9 & 1 \\
\hline Congestive heart failure & $428-428.9$ & 1 \\
\hline Peripheral vascular disease & $433.9,441-441.9,785.4, V 43.4$ & 1 \\
\hline Cerebrovascular disease & $430-438$ & 1 \\
\hline Dementia & $290-290.9$ & 1 \\
\hline Chronic pulmonary disease & $490-496,500-505,506.4$ & 1 \\
\hline Rheumatologic disease & $710.0,710.1,710.4,714.0-714.2,714.81,725$ & 1 \\
\hline Peptic ulcer disease & $531-534.9$ & 1 \\
\hline Mild liver disease & $571.2,571.5,571.6,571.4-571.49$ & 1 \\
\hline Diabetes & $250-250.3,250.7$ & 1 \\
\hline Diabetes with chronic complications & $250.4-250.6$ & 2 \\
\hline Hemiplegia or paraplegia & $344.1,342-342.9$ & 2 \\
\hline Renal disease & $582-582.9,583-583.7,585,586,588-588.9$ & 2 \\
\hline Any malignancy including leukemia and lymphoma & $140-172.9,174-195.8,200-208.9$ & 2 \\
\hline Moderate or severe liver disease & $572.2-572.8$ & 3 \\
\hline Metastatic solid tumor & 196-199.1 & 6 \\
\hline AlDS & 042-044.9 & 6 \\
\hline
\end{tabular}

\section{TABLE 1: Deyo's modification of CCI}

CCI, Charlson comorbidity index; ICD-9-CM, International Classification of Diseases, Ninth Revision, Clinical Modification

\section{The outcomes}

The primary outcome of interest was to determine if opioid abuse among patients hospitalized for migraine, TTH, or CH during 2008-2014 was associated with differences in morbidity, disability, or discharge disposition. Morbidity was defined as patients transferred to a short-term hospital (STH), or skilled nursing facility (SNF), or intermediate care facility (ICF) and a hospital stay of more than eight days (>90th percentile of mean headache hospitalizations). The comparison of disability/loss of function was investigated by All Patient Refined Diagnosis Related Group (APR-DRG) severity between patients with opioid abuse and patients without opioid abuse. APR-DRGs were assigned using software developed by 3M Health Information Systems (Salt Lake City, UT), where score 0 indicates no loss of function, 1 indicates minor, 2 moderate, 3 major, and 4 indicates extreme loss of function. Detailed information on APR-DRGs is available at https://hcup-us.ahrq.gov/db/vars/aprdrg_severity/nisnote.jsp. Our secondary outcome of interest was to evaluate whether opioid-dependent and non-dependent opioid abuse was associated with headache disorders among patients hospitalized in the US between January 2013 and December 2014. The reason to choose the year 2013-2014 data for secondary outcome was a large number of US hospitalizations (more than 20 million) each year to evaluate patients with and without opioid abuse and headache disorders.

\section{Statistical analysis}

All statistical analyses were performed using the weighted survey methods in SAS version 9.4 (SAS Institute Inc., Cary, $\mathrm{NC}$ ). Weighted values of patient-level observations were generated to produce a nationally representative estimate of the entire US population of hospitalized patients. A p-value of $<0.05$ was considered significant. Univariate analysis of differences between categorical variables was tested using the chi-square test, and analysis of differences between a continuous variable (age) was tested using paired Student's t-test. Mixed-effects survey logistic regression models with weighted analysis were used for categorical dependent variables to estimate the odds ratio (OR) and 95\% confidence intervals for the association between opioid use and outcomes of interest among headache disorders from January 2008 to December 2014 and for the linkage between opioid use and headache disorders from January 2013 to December 2014. 


\section{Cureus}

We adjusted models with demographics (age, gender, race), patient-level hospitalization variables (admission day, primary payer, admission type, median household income category), hospital-level variables (hospital region, teaching versus non-teaching hospital, hospital bedsize), and CCI.

For each model, the c-index (a measure of goodness of fit for binary outcomes in a logistic regression model) was calculated. All statistical tests used were two-sided, and $\mathrm{p}<0.05$ was deemed statistically significant. No statistical power calculation was conducted prior to the study.

\section{Data availability}

The data that supports the findings of this study is publicly available from the Agency for Healthcare Research and Quality's HCUP-NIS. A raw analysis of the data will be however made available from the authors upon request and with permission from HCUP-NIS.

\section{Results}

\section{Disease hospitalizations}

From 2008 to 2014, after excluding patients with age $<18$ years and admissions with missing data for age, gender, and ethnicity, we found a total of 5,627,936 hospitalizations with headache disorders. Out of them, 128,383 (2.28\%) were opioid abusers, 3,098,542 (55.06\%) had migraine, 113,332 (2.01\%) had TTH, and $26,572(0.47 \%)$ had CH.

\section{Trends and prevalence}

We analyzed trends of opioid abuse in total headache hospitalizations as well as in hospitalizations due to migraine, TTH, and CH. As shown in Figure 1, trends of opioid abuse were increasing from 2008 to 2014 in headache hospitalizations ( $1.74 \%$ in 2008 to $2.71 \%$ in 2014 ; p-trend<0.0001). We also found increased opioid abuse trends from 2008 to 2014 in migraine (2.08\% in 2008 to $3.05 \%$ in 2014 ; p-trend<0.0001), TTH (1.60\% in 2008 to $3.38 \%$ in 2014; p-trend<0.0001), and CH (2.74\% in 2008 to 3.62\% in 2013 and 2.58\% in 2014; nonsignificant p-trend=0.3821). The opioid abusers had higher prevalence of migraine [81,573 (63.54\%) vs. 3,016,969 (54.86\%); p<0.0001], TTH [2943 (2.29\%) vs. 110,389 (2.01\%); p<0.0001], and CH [753 (0.59\%) vs. $25,819$ (0.47\%); $<<0.0001]$ compared to non-abusers (Table 2).

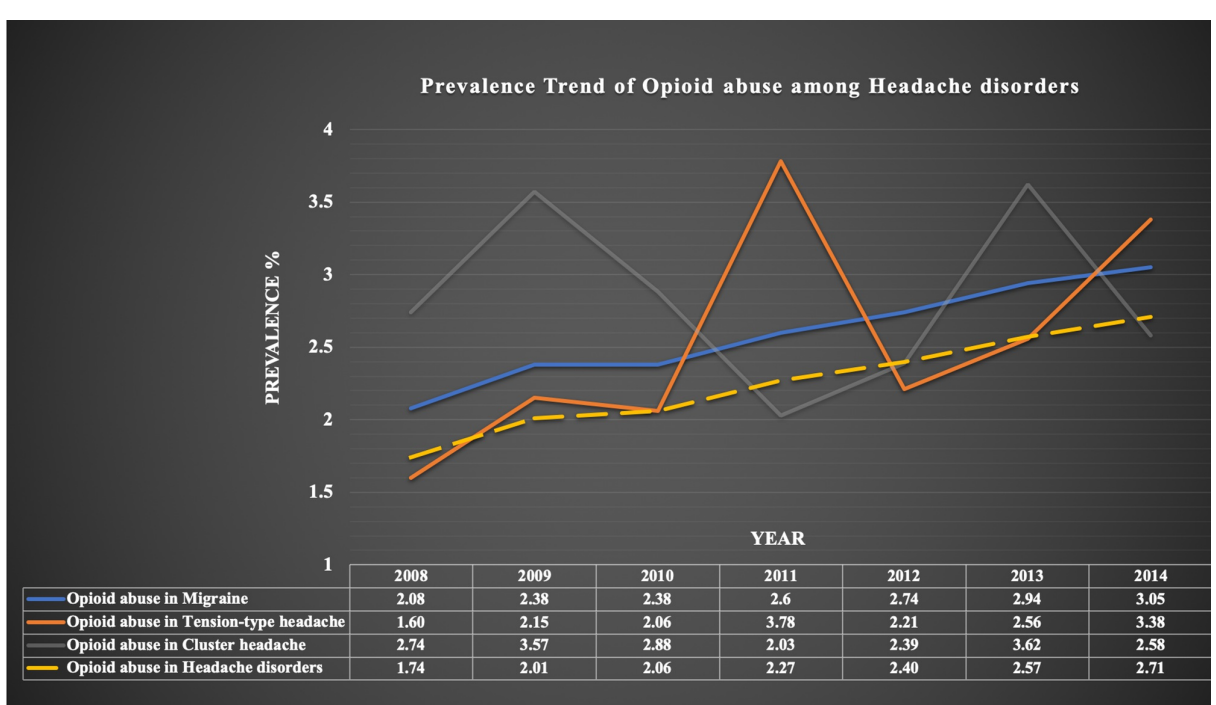

FIGURE 1: Trends of opioid abuse among patients with headache disorders

US hospitalization weighted, n (\%)

Migraine

Tension-type headache

Cluster headache

\begin{tabular}{|l|l|l|l|}
\hline $\begin{array}{l}\text { Opioid } \\
\text { abusers }\end{array}$ & $\begin{array}{l}\text { Opioid non- } \\
\text { abusers }\end{array}$ & Total & p-value \\
\hline $128,383(2.28)$ & $5,499,553(97.72)$ & $5,627,936(100)$ & $<0.0001$ \\
\hline $81,573(63.54)$ & $3,016,969(54.86)$ & $3,098,542(55.06)$ & $<0.0001$ \\
\hline $2943(2.29)$ & $110,389(2.01)$ & $113,332(2.01)$ & $<0.0001$ \\
\hline $753(0.59)$ & $25,819(0.47)$ & $26,572(0.47)$ & $<0.0001$ \\
\hline
\end{tabular}




\section{Cureus}

Demographics of patients

Age median (SD) (years)

$43(13)$

50 (17)

Age group (years), $\mathrm{n}(\%)$

18-34

41,421 (32.26)

1,141,799 (20.76)

$1,183,220$ (21.02)

35-49

45,403 (35.37)

$1,591,363$ (28.94)

$1,636,766(29.08)$

50-64

34,622 (26.97)

$1,616,162(29.39)$

$1,650,784$ (29.33)

65-79

$6294(4.90)$

835,166 (15.19)

$841,460(14.95)$

$\geq 80$

$644(0.50)$

315,064 (5.73)

$315,708(5.61)$

Gender, n (\%)

Male

$38,739(30.17)$

$1,362,635$ (24.78)

$1,401,374(24.90)$

Female

$89,644(69.83)$

4,136,766 (75.22)

$4,226,410$ (75.10)

Race, n (\%)

101,681

White

(80.83)

$3,921,186$ (73.29)

$4,022,867(73.46)$

African American

$14,266(11.34)$

791,546 (14.79)

$805,812(14.71)$

Hispanic

8269 (6.57)

$518,840(9.70)$

$527,109(9.63)$

Asian or Pacific Islander

$655(0.52)$

84,835 (1.59)

$85,490(1.56)$

Native American

$929(0.74)$

$34,090(0.64)$

$35,019(0.64)$

Characteristics of patients

Median household income category for patient's Zip code, $\mathrm{n}$

(\%)

0-25th percentile

35,622 (28.62)

$1,515,526(28.18)$

$1,551,148(28.19)$

26th-50th percentile

$31,671(25.45)$

$1,380,674$ (25.67)

$1,412,345$ (25.67)

51st-75th percentile

$30,476(24.49)$

$1,317,011(24.49)$

$1,347,487$ (24.49)

76th-100th percentile

26,691 (21.45)

$1,164,911$ (21.66)

$1,191,602(21.66)$

Primary payer, n (\%)

34,266 (26.74)

1,716,332 (31.28)

$1,750,598$ (31.17)

Medicare

38,639 (30.15)

$934,375(17.03)$

$973,014(17.33)$

35,039 (27.34)

$2,209,402(40.26)$

$2,244,441$ (39.97)

20,224 (15.78)

627,538 (11.44)

$647,762(11.53)$

Other/self-pay/no charge

Admission type, $\mathrm{n}(\%)$

Non-elective

109,357 (85.40) $\quad 4,305,363$ (78.51)

$4,414,720$ (78.66)

Elective

$18,689(14.60) \quad 1,178,689(21.49)$

$1,197,378(21.34)$

Admission day, $\mathrm{n}(\%)$

100,018 (77.91) $\quad 4,411,250(80.21)$

$4,511,268(80.16)$

Weekday

28,365 (22.09) $\quad 1,088,294$ (19.79)

$1,116,659(19.84)$

Weekend

Characteristics of hospitals

Bedsize of hospital, $\mathrm{n}(\%)^{\star}$

$<0.0001$

Small

$16,580(12.98)$

722,460 (13.23)

739,040 (13.22)

Medium

$33,110(25.93) \quad 1,374,792(25.17)$

$1,407,902$ (25.19)

$<0.0001$

$<0.0001$

$<0.0001$ 


\section{Cureus}

\begin{tabular}{|c|c|c|c|c|}
\hline Large & $78,004(61.09)$ & $3,365,141(61.61)$ & $3,443,145(61.59)$ & \\
\hline Hospital location and teaching status, $n(\%)$ & & & & $<0.0001$ \\
\hline Rural & $9750(7.64)$ & $548,194(10.04)$ & $557,944(9.98)$ & \\
\hline Urban non-teaching & $52,173(40.86)$ & $2,111,699(38.66)$ & $2,163,872(38.71)$ & \\
\hline Urban teaching & $65,771(51.51)$ & $2,802,500(51.31)$ & $2,868,271(51.31)$ & \\
\hline Hospital region, n (\%) & & & & $<0.0001$ \\
\hline Northeast & 28,729 (22.38) & $1,016,819(18.49)$ & $1,045,548(18.58)$ & \\
\hline Midwest & 23,461 (18.27) & $1,133,058(20.60)$ & $1,156,519(20.55)$ & \\
\hline South & $45,175(35.19)$ & $2,277,278(41.41)$ & $2,322,453(41.27)$ & \\
\hline West & $31,018(24.16)$ & $1,072,398(19.50)$ & $1,103,416(19.61)$ & \\
\hline Deyo's CCl, n (\%) & & & & $<0.0001$ \\
\hline 0 & $71,861(55.97)$ & $2,634,272(47.90)$ & $2,706,133(48.08)$ & \\
\hline 1 & $33,153(25.82)$ & $1,470,737(26.74)$ & $1,503,890(26.72)$ & \\
\hline 2 & $11,878(9.25)$ & 688,501 (12.52) & 700,379 (12.44) & \\
\hline 3 & $5250(4.09)$ & 307,168 (5.59) & 312,418 (5.55) & \\
\hline 4 & $2338(1.82)$ & $153,580(2.79)$ & $155,918(2.77)$ & \\
\hline$\geq 5$ & $3904(3.04)$ & $245,294(4.46)$ & 249,198 (4.43) & \\
\hline
\end{tabular}

\section{TABLE 2: Characteristics of opioid abusers among patients with primary headache disorders}

$\mathrm{CCl}$, Charlson comorbidity index. Percentages in parentheses are column \% indicating a direct comparison between opioid abusers and opioid non-abusers among patients with headache disorders.

*Bedsize of hospital indicates the number of hospital beds that varies depending on hospital location (rural/urban), teaching status (teaching/nonteaching), and region (Northeast/Midwest/Southern/Western).

\section{Demographics, patient and hospital characteristics, and comorbidities}

Opioid abuse was more common in the $18-49$ years of age group $(p<0.0001)$. The individuals with opioid abuse were more likely to be males ( $30.17 \%$ vs. $24.78 \%$; $\mathrm{p}<0.0001)$, white $(80.83 \%$ vs. $73.29 \%$; $\mathrm{p}<0.0001)$, Medicaid users (30.15\% vs. $17.03 \%$; $\mathrm{p}<0.0001)$, and non-elective admissions $(85.40 \%$ vs. $78.51 \%$; $\mathrm{p}<0.0001)$ compared to individuals without opioid abuse.

\section{The outcomes}

Table 3 mentions outcomes of opioid abusers among patients with headache hospitalizations. The overall morbidity was higher in opioid abusers $(4.06 \%$ vs $3.70 \%$; $\mathrm{p}<0.0001)$ than opioid non-abusers. Among headache hospitalizations, there was a higher prevalence of major/severe loss of function in opioid abusers compared to opioid non-abusers ( $28.14 \%$ vs. $22.43 \%$; $\mathrm{p}<0.0001)$. There was a higher prevalence of opioid abusers who were transferred to short-term hospitalization $(2.01 \%$ vs. $1.75 \%$; $\mathrm{p}<0.0001)$ and transferred to a skilled nursing facility or intermediate care facility $(8.84 \%$ vs. $7.33 \%$; $\mathrm{p}<0.0001)$. 


\section{Cureus}

\begin{tabular}{|c|c|c|c|c|}
\hline & Opioid abusers & Opioid non-abusers & Total & p-value \\
\hline Morbidity, n (\%)* & $5210(4.06)$ & $203,567(3.70)$ & $208,777(3.71)$ & $<0.0001$ \\
\hline APR-DRG severity or disability/loss of function, $n(\%)$ & & & & $<0.0001$ \\
\hline No loss of function & $\leq 10$ & $825(0.02)$ & $835(0.01)$ & \\
\hline Minor loss of function & 24,462 (19.14) & $1,704,852(31.14)$ & $1,729,314(30.87)$ & \\
\hline Moderate loss of function & $67,376(52.71)$ & $2,541,186(46.42)$ & $2,608,562(46.56)$ & \\
\hline Major loss of function & $30,579(23.92)$ & $1,077,846(19.69)$ & $1,108,425(19.78)$ & \\
\hline Severe loss of function & $5392(4.22)$ & $150,151(2.74)$ & $155,543(2.78)$ & \\
\hline Total major/severe loss of function (\%) & 35,971 (28.14) & $1,227,997(22.43)$ & $1,263,968(22.56)$ & $<0.0001$ \\
\hline Discharge disposition, $\mathrm{n}(\%)$ & & & & $<0.0001$ \\
\hline Routine/home & $100,831(82.87)$ & $4,406,565(81.59)$ & $4,507,396(81.62)$ & \\
\hline Transfer to STH & $2444(2.01)$ & $94,652(1.75)$ & $97,096(1.76)$ & \\
\hline Transfer to SNF/ICF/another type of facility & $10,752(8.84)$ & $396,005(7.33)$ & 406,757 (7.37) & \\
\hline Home health care & $7644(6.28)$ & $503,787(9.33)$ & $511,431(9.26)$ & \\
\hline Total discharge other than home & $20,840(17.13)$ & $994,443(18.41)$ & $1,015,283(18.38)$ & $<0.0001$ \\
\hline
\end{tabular}

\section{TABLE 3: Univariate analysis of outcomes of opioid abusers among patients with primary headache disorders}

APR-DRG, All Patients Refined Diagnosis Related Group; STH, short-term hospital, SNF, skilled nursing facility; ICF, intermediate care facility; SE, standard error. Percentages in parentheses are column \% indicating a direct comparison between opioid abusers and opioid non-abusers among patients with headache disorders.

*Morbidity: length of stay $>8$ days (>90 percentile of mean headache hospitalizations) and discharge other than home (STH, SNF, or ICF).

\section{Regression model derivation}

We performed the multivariable survey logistic regression models to predict the outcomes of opioid abusers (morbidity, disability, and discharge disposition) among patients with headache disorders after adjusting for basic demographic characteristics with patient and hospital-level variables, and CCI (Table 4). In this multivariate regression analysis, opioid abusers had higher odds of morbidity (adjusted OR [aOR]: 1.48; 95\% CI: $1.39-1.59$; $\mathrm{p}<0.0001$ ) compared to opioid non-abusers. Similarly, opioid abusers also had higher odds of major/severe disability (aOR: 1.58; 95\% CI: 1.53-1.63; p<0.0001), and discharge to short-term hospital or skilled nursing facility or intermediate care facility (aOR: 1.35 ; 95\% CI: $1.30-1.40 ; \mathrm{p}<0.0001$ ) compared to opioid non-abusers (Table 4).

\begin{tabular}{|c|c|c|c|}
\hline & $\begin{array}{l}\text { Model 1: odds of } \\
\text { morbidity* }\end{array}$ & $\begin{array}{l}\text { Model 2: odds of major or } \\
\text { severe disability }{ }^{\dagger}\end{array}$ & $\begin{array}{l}\text { Model 3: odds of non-home } \\
\text { discharge disposition }{ }^{\ddagger}\end{array}$ \\
\hline & OR; Cl; p-value & OR; Cl; p-value & OR; Cl; p-value \\
\hline No opioid abuse & \multicolumn{3}{|l|}{ Reference } \\
\hline Opioid abuse & $\begin{array}{l}1.48 ; 1.39-1.59 \\
<0.0001\end{array}$ & $1.58 ; 1.53-1.63 ;<0.0001$ & $1.35 ; 1.30-1.40 ;<0.0001$ \\
\hline Age (every 10 years) & $\begin{array}{l}\text { 1.02; 1.02-1.02; } \\
<0.0001\end{array}$ & $1.00 ; 1.00-1.00 ;<0.0001$ & $1.04 ; 1.04-1.04 ;<0.0001$ \\
\hline \multicolumn{4}{|l|}{ Gender } \\
\hline Female & Reference & & \\
\hline Male & $\begin{array}{l}\text { 1.16; 1.14-1.19; } \\
<0.0001\end{array}$ & $1.12 ; 1.11-1.13 ;<0.0001$ & $0.95 ; 0.94-0.96 ;<0.0001$ \\
\hline
\end{tabular}




\section{Cureus}

\begin{tabular}{|c|c|c|c|}
\hline \multicolumn{4}{|l|}{ Race } \\
\hline White & \multicolumn{3}{|l|}{ Reference } \\
\hline African American & $\begin{array}{l}0.97 ; 0.94-1.00 \\
0.0792\end{array}$ & $0.92 ; 0.91-0.94 ;<0.0001$ & $0.94 ; 0.92-0.95 ;<0.0001$ \\
\hline Hispanic & $\begin{array}{l}0.90 ; 0.86-0.93 \\
<0.0001\end{array}$ & $0.82 ; 0.80-0.83 ;<0.0001$ & $0.77 ; 0.76-0.79 ;<0.0001$ \\
\hline Asian or Pacific Islander & $\begin{array}{l}1.10 ; 1.02-1.19 \\
0.0163\end{array}$ & $0.92 ; 0.88-0.96 ;<0.0001$ & $0.82 ; 0.78-0.85 ;<0.0001$ \\
\hline Native American & $\begin{array}{l}0.86 ; 0.73-1.00 \\
0.0479\end{array}$ & $0.92 ; 0.87-0.98 ; 0.0118$ & $0.84 ; 0.78-0.90 ;<0.0001$ \\
\hline \multicolumn{4}{|c|}{$\begin{array}{l}\text { Median household income category for } \\
\text { patient's Zip code }\end{array}$} \\
\hline $0-25$ th percentile & Reference & & \\
\hline 26th-50th percentile & $\begin{array}{l}0.99 ; 0.96-1.02 \\
0.5295\end{array}$ & $1.01 ; 0.99-1.02 ; 0.2527$ & $0.99 ; 0.98-1.01 ; 0.2400$ \\
\hline 51st-75th percentile & $\begin{array}{l}0.97 ; 0.94-0.99 ; \\
0.0201\end{array}$ & $1.04 ; 1.02-1.05 ;<0.0001$ & $0.99 ; 0.97-1.00 ; 0.0626$ \\
\hline 76th-100th percentile & $\begin{array}{l}0.95 ; 0.92-0.98 \\
0.0030\end{array}$ & $1.05 ; 1.04-1.07 ;<0.0001$ & $0.99 ; 0.98-1.01 ; 0.4194$ \\
\hline \multicolumn{4}{|l|}{ Primary payer } \\
\hline Medicare & Reference & & \\
\hline Medicaid & $\begin{array}{l}0.85 ; 0.82-0.88 \\
<0.0001\end{array}$ & $0.81 ; 0.79-0.82 ;<0.0001$ & $0.77 ; 0.75-0.78 ;<0.0001$ \\
\hline Private insurance & $\begin{array}{l}0.63 ; 0.61-0.65 \\
<0.0001\end{array}$ & $0.66 ; 0.65-0.67 ;<0.0001$ & $0.60 ; 0.59-0.61 ;<0.0001$ \\
\hline Other/self-pay/no charge & $\begin{array}{l}0.51 ; 0.48-0.53 \\
<0.0001\end{array}$ & $0.61 ; 0.59-0.62 ;<0.0001$ & $0.49 ; 0.48-0.50 ;<0.0001$ \\
\hline \multicolumn{4}{|l|}{ Admission type } \\
\hline Non-elective & Reference & & \\
\hline Elective & $\begin{array}{l}1.40 ; 1.37-1.44 \\
<0.0001\end{array}$ & $0.63 ; 0.62-0.64 ;<0.0001$ & $1.59 ; 1.57-1.61 ;<0.0001$ \\
\hline \multicolumn{4}{|l|}{ Admission day } \\
\hline Weekday & Reference & & \\
\hline Weekend & $\begin{array}{l}1.10 ; 1.07-1.13 \\
<0.0001\end{array}$ & $1.06 ; 1.04-1.07 ;<0.0001$ & $1.00 ; 0.99-1.01 ; 0.8087$ \\
\hline \multicolumn{4}{|l|}{ Bedsize of hospital } \\
\hline Small & Reference & & \\
\hline Medium & $\begin{array}{l}1.17 ; 1.31-1.22 \\
<0.0001\end{array}$ & $1.09 ; 1.07-1.10 ;<0.0001$ & $0.98 ; 0.96-1.00 ; 0.0188$ \\
\hline Large & $\begin{array}{l}1.46 ; 1.41-1.51 \\
<0.0001\end{array}$ & $1.19 ; 1.17-1.21 ;<0.0001$ & $0.97 ; 0.96-0.99 ; 0.0006$ \\
\hline \multicolumn{4}{|c|}{ Hospital location and teaching status } \\
\hline Rural & Reference & & \\
\hline \multirow[t]{2}{*}{ Urban non-teaching } & $\begin{array}{l}1.49 ; 1.42-1.55 \\
<0.0001\end{array}$ & $1.11 ; 1.09-1.13 ;<0.0001$ & $1.09 ; 1.06-1.11 ;<0.0001$ \\
\hline & 1.86; 1.79-1.94; & & \\
\hline
\end{tabular}




\section{Cureus}

$\begin{array}{llll}\text { Urban teaching } & <0.0001 & 1.42 ; 1.40-1.45 ;<0.0001 & 1.09 ; 1.07-1.11 ;<0.0001 \\ \text { Hospital region } & & & \\ \text { Northeast } & \text { Reference } & & \\ \text { Midwest } & 0.88 ; 0.86-0.91 ; & 1.42 ; 1.40-1.44 ;<0.0001 & 0.76 ; 0.75-0.77 ;<0.0001 \\ & <0.0001 & & \\ \text { South } & 0.85 ; 0.83-0.88 ; & 1.41 ; 1.39-1.43 ;<0.0001 & 0.69 ; 0.68-0.70 ;<0.0001 \\ & <0.0001 & & 0.70 ; 0.69-0.71 ;<0.0001 \\ \text { West } & 0.81 ; 0.78-0.84 ; & 1.59 ; 1.57-1.62 ;<0.0001 & \\ & <0.0001 & & 1.18 ; 1.17-.1 .18 ;<0.0001 \\ \text { Deyo's CCI } & 1.24 ; 1.23-1.24 ; & 1.54 ; 1.54-1.55 ;<0.0001 & 0.74 \\ \text { c-index } & <0.0001 & 0.73 & \end{array}$

TABLE 4: Multivariable logistic regression analysis to predict outcomes of opioid abusers among patients with primary headache disorders

OR, odds ratio; CCI, Charlson comorbidity index; STH, short-term hospital, SNF, skilled nursing facility; ICF, intermediate care facility; APR-DRG, All Patients Refined Diagnosis Related Group

*Morbidity was defined as length of stay $>8$ days ( $>90$ percentile of mean headache hospitalizations) and discharge other than home (STH, SNF, or ICF).

${ }^{\dagger}$ Disability was defined by major/severe APR-DRG loss of function on discharge.

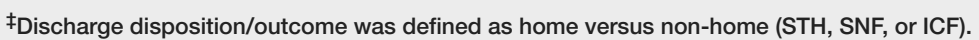

\section{Accuracy of the model}

Adjusted models to predict morbidity, disability, and discharge disposition had the c-statistic of $0.73,0.73$, and 0.74 , respectively, which are $>0.7$ indicating a good model.

\section{Analysis to predict the linkage between headache disorders and opioid abuse from January 2013 to December 2014}

From January 2013 to December 2014, a total of 56,581,503 hospitalizations were analyzed. Among them, 978,860 (1.73\%) patients had a history of opioid abuse. There was a higher prevalence of opioid abuse among migraineurs compared to non-migraineurs ( $3.00 \%$ vs. $1.71 \%$; $\mathrm{p}<0.0001)$, patients with TTH compared to without TTH ( $2.97 \%$ vs. $1.73 \%$; $<0.0001)$, and patients with $\mathrm{CH}$ compared to without $\mathrm{CH}$ ( $3.10 \%$ vs. $1.73 \%$; $\mathrm{p}<0.0001$ ) (Table 5).

Linkage between primary headache disorders and opioid abuse

Migraine vs. no migraine among opioid abusers

$29485(3.00 \%)$ vs. $949375(1.71 \%)(p<0.0001)$

Tension-type headache vs. no tension-type headache among opioid abusers $960(2.97 \%)$ vs. $977900(1.73 \%)(p<0.0001)$

Cluster headache vs. no cluster headache among opioid abusers $275(3.10 \%)$ vs. $978585(1.73 \%)(p<0.0001)$

TABLE 5: Univariate analysis of the linkage between primary headache disorders and opioid abuse

In the regression analysis, after adjusting for basic demographics with the patients and hospital-level variables, and CCI, patients with migraine (aOR: 1.61; 95\% CI: 1.57-1.66; p<0.0001), TTH (aOR: 1.43; 95\% CI: 1.22-1.66; $\mathrm{p}<0.0001$ ), and $\mathrm{CH}$ (aOR: 1.34; 95\% CI: 1.01-1.78; $\mathrm{p}=0.0421$ ) were having higher odds of exposure to opioid abuse than patients without these headache disorders (Table ๑). The c-statistic was 0.78 , which indicates a good model. 


\section{Cureus}

\begin{tabular}{|c|c|c|c|c|}
\hline & \multirow[t]{2}{*}{ OR } & \multicolumn{2}{|l|}{ Cl } & \multirow[t]{2}{*}{ p-value } \\
\hline & & LL & UL & \\
\hline No migraine & \multicolumn{3}{|c|}{ Reference } & \\
\hline Migraine & 1.61 & 1.57 & 1.66 & $<0.0001$ \\
\hline No tension-type headache & \multicolumn{3}{|c|}{ Reference } & \\
\hline Tension-type headache & 1.43 & 1.22 & 1.66 & $<0.0001$ \\
\hline No cluster headache & \multicolumn{2}{|c|}{ Reference } & & \\
\hline Cluster headache & 1.34 & 1.01 & 1.78 & 0.0421 \\
\hline Age (every 10 years) & 0.96 & 0.96 & 0.96 & $<0.0001$ \\
\hline \multicolumn{5}{|l|}{ Gender } \\
\hline remale & \multicolumn{3}{|c|}{ Reference } & \\
\hline Male & 1.92 & 1.90 & 1.94 & $<0.0001$ \\
\hline \multicolumn{5}{|l|}{ Race } \\
\hline White & \multicolumn{3}{|c|}{ Reference } & \\
\hline African American & 0.59 & 0.58 & 0.60 & $<0.0001$ \\
\hline Hispanıc & 0.38 & 0.38 & 0.39 & $<0.0001$ \\
\hline Asıan or Pacitıc Islander & 0.16 & 0.15 & 0.16 & $<0.0001$ \\
\hline Native American & 0.76 & 0.72 & 0.80 & $<0.0001$ \\
\hline \multicolumn{5}{|c|}{ Median household income category for patient's Zip code } \\
\hline 0-25th percentile & \multicolumn{2}{|c|}{ Reference } & & \\
\hline 26th-50th percentile & 0.81 & 0.80 & 0.82 & $<0.0001$ \\
\hline 51st-75th percentile & 0.79 & 0.78 & 0.80 & $<0.0001$ \\
\hline 76th-100th percentile & 0.77 & 0.76 & 0.79 & $<0.0001$ \\
\hline \multicolumn{5}{|l|}{ Primary payer } \\
\hline Medicare & \multicolumn{3}{|c|}{ Reference } & \\
\hline Medicaid & 1.72 & 1.69 & 1.75 & $<0.0001$ \\
\hline Private insurance & 0.54 & 0.53 & 0.55 & $<0.0001$ \\
\hline Other/self-pay/no charge & 1.41 & 1.38 & 1.44 & $<0.0001$ \\
\hline \multicolumn{5}{|l|}{ Admission type } \\
\hline Non-elective & \multicolumn{2}{|c|}{ Reference } & & \\
\hline Elective & 0.53 & 0.52 & 0.54 & $<0.0001$ \\
\hline \multicolumn{5}{|l|}{ Admission day } \\
\hline Weekday & \multicolumn{3}{|c|}{ Reference } & \\
\hline Weekend & 1.03 & 1.02 & 1.04 & $<0.0001$ \\
\hline \multicolumn{5}{|l|}{ Bedsize of hospital } \\
\hline Small & \multicolumn{2}{|c|}{ Reference } & & \\
\hline Medium & 0.91 & 0.90 & 0.93 & $<0.0001$ \\
\hline Large & 0.90 & 0.89 & 0.91 & $<0.0001$ \\
\hline
\end{tabular}




\section{Cureus}

\begin{tabular}{|c|c|c|c|c|}
\hline Rural & \multicolumn{4}{|c|}{ Reference } \\
\hline Urban non-teaching & 1.40 & 1.37 & 1.42 & $<0.0001$ \\
\hline Urban teaching & 1.43 & 1.40 & 1.45 & $<0.0001$ \\
\hline \multicolumn{5}{|l|}{ Hospital region } \\
\hline Northeast & \multicolumn{4}{|c|}{ Reference } \\
\hline Midwest & 0.61 & 0.60 & 0.62 & $<0.0001$ \\
\hline South & 0.49 & 0.48 & 0.49 & $<0.0001$ \\
\hline West & 0.76 & 0.75 & 0.77 & $<0.0001$ \\
\hline Deyo's CCl & 0.94 & 0.94 & 0.95 & $<0.0001$ \\
\hline c-index & 0.78 & & & \\
\hline
\end{tabular}

TABLE 6: Adjusted multivariable logistic regression analysis to predict the linkage between primary headache disorders and opioid abuse

OR, odds ratio; UL, upper limit; LL, lower limit; CCI, Charlson comorbidity index

\section{Discussion}

Headache is the most common neurological disorder presenting to primary care, accounting for $3 \%$ of all visits [9]. In 2007, Stovner et al. reported a global prevalence of $46 \%$ for headache in general, $11 \%$ for migraine, $42 \%$ for tension-type headache, and 3\% for chronic daily headache [10]. In 2015, the Global Burden of Disease estimated that headache disorders including their subtypes - migraine, TTH, and $\mathrm{CH}$ - were the third cause of disability in people less than 50 years of age [11]. Opioid abuse is of particular concern in headache disorders given its role as a treatment modality. Over the last two decades, the opioid epidemic has led to enormous health concerns and it has been triggered to a large extent by prescription opioids: an $80 \%$ increase in opioid analgesic prescriptions from the year 2000 through 2010 with incremental use from $7.4 \%$ to $11.8 \%$ [12]. Similarly, in our study, we found that among the adult American population, opioid use increased from $1.74 \%$ in 2008 to $2.71 \%$ in 2014 .

In recent years, there has been a tremendous increase in opioid prescriptions for acute and chronic pain and this trend is also seen in patients with headache disorders [13]. The American Migraine Prevalence and Prevention Study (AMPP) involving 6008 migraine patients reported that $16.6 \%$ of patients met Diagnostic and Statistical Manual of Mental Disorders, Fourth Edition (DSM-IV) criteria for opioid dependence [14]. A study by Choong et al. reported that the most common medicine prescribed for cluster headache is opioids [15]. Our study found that among 5,627,936 headache hospitalizations, 128,383 (2.28\%) were opioid abusers. We also found a significant increasing trend of opioid abuse (years 2008-2014) among headache hospitalizations (1.74\% in 2008 to $2.71 \%$ in 2014; p-trend<0.0001). This recent trend in overprescribing opioids for various headache disorders despite the lack of strong evidence showing the efficacy of opioid treatment has led to serious consequences both affecting an individual's quality of life and increased burden on society and healthcare that must now be addressed conscientiously.

Opioid use can also lead to significantly higher disability in patients admitted for headaches. Our study also found 1.48 times higher odds of morbidity and 1.58 times higher odds of major/severe disability among opioid abusers compared to opioid non-abusers $(\mathrm{p}<0.0001)$. This increased disability can be due to chronic opioid therapy in treating chronic migraine and as prophylaxis for refractory headache. Considering the risks including disability, low quality of life, and higher healthcare costs associated with opioid abuse and lack of opioid efficacy data in the treatment of migraine, it is crucial for providers to evaluate potential benefits of alternate treatment options. Several guidelines have been published for the safe use of opioid medications in the treatment of chronic pain that emphasize screening prior to prescribing opioids [16,17].

To prevent opioid abuse and its associated adverse effects, it is crucial that the patient's medication regimen is reviewed at each visit as well as screening for impaired cognition, use of other illicit or prescription drugs, and concurrent mental illness has been done as all of these factors may increase the risk of opioid overdose [18]. Among patients treated with chronic opioids, a urine toxicology screen should be done at the first clinic visit and then annually to assess for potential polysubstance abuse [19].

\section{Strength and limitations}

To our knowledge, this is the first large population-based nationwide study to report prevalence, outcomes, 
and linkage between opioid abuse and headache disorders. One of the limitations of this study being an observational study is that we cannot prove causation of the temporal association of opioids for headache disorders. Also, our assessment is limited to hospitalized patients with headaches and may not reflect the severity of the issue in outpatients. Long-term outcomes are also not available through this study. In spite of these limitations, we have a very large number of patients in the study, which is possible through the use of a nationwide database such as NIS. The APR-DRG coding system used in this study to assess the severity of illness is an external validated reliable method with accurate and consistent results and is widely used by hospitals [20,21]. A population-wide study with a large number of subjects is ideally suited to understand the impact of the opioid epidemic on headache disorders.

\section{Conclusions}

We have found that opioid abusers were associated with the higher prevalence of migraine, TTH, and $\mathrm{CH}$ and also had higher odds of morbidity, severe disability, and non-home discharge as compared to non-abusers. The patients with these primary headache disorders were having higher odds of exposure to opioid abuse than patients without these headache disorders. A careful selection of patients for opioid prescription and refill, counselling for recreational use, and identification of such patients might mitigate the risk of opioid abuse-associated poor outcomes among patients with headache disorders.

\section{Additional Information}

\section{Disclosures}

Human subjects: All authors have confirmed that this study did not involve human participants or tissue. Animal subjects: All authors have confirmed that this study did not involve animal subjects or tissue. Conflicts of interest: In compliance with the ICMJE uniform disclosure form, all authors declare the following: Payment/services info: All authors have declared that no financial support was received from any organization for the submitted work. Financial relationships: All authors have declared that they have no financial relationships at present or within the previous three years with any organizations that might have an interest in the submitted work. Other relationships: All authors have declared that there are no other relationships or activities that could appear to have influenced the submitted work.

\section{References}

1. Global Burden of Disease Study 2013 Collaborators: Global, regional, and national incidence, prevalence, and years lived with disability for 301 acute and chronic diseases and injuries in 188 countries, 1990-2013: a systematic analysis for the Global Burden of Disease Study 2013. Lancet. 2015, 386:743-800. 10.1016/s01406736(15)60692-4

2. Knox J, Chuni C, Naqvi Z, Crawford P, Waring W: Presentations to an acute medical unit due to headache: a review of 306 consecutive cases. Acute Med. 2012, 11:144-149.

3. Steiner TJ, Stovner LJ, Vos T, Jensen R, Katsarava Z: Migraine is first cause of disability in under 50s: will health politicians now take notice?. J Headache Pain. 2018, 19:17. 10.1186/s10194-018-0846-2

4. Lanteri-Minet M, Duru G, Mudge M, Cottrell S: Quality of life impairment, disability and economic burden associated with chronic daily headache, focusing on chronic migraine with or without medication overuse: a systematic review. Cephalalgia. 2011, 31:837-850. 10.1177/0333102411398400

5. Connelly M, Sekhon S: Current perspectives on the development and treatment of chronic daily headache in children and adolescents. Pain Manag. 2019, 9:175-189. 10.2217/pmt-2018-0057

6. de Leon-Casasola OA: Opioids for chronic pain: new evidence, new strategies, safe prescribing . Am J Med. 2013, 126:3-11.10.1016/j.amjmed.2012.11.011

7. Patel UK, Malik P, Sheth R, et al.: Fibromyalgia and myositis linked to higher burden and disability in patients with migraine. SN Compr Clin Med. 2019, 1:882-890. 10.1007/s42399-019-00129-7

8. Patel U, Kodumuri N, Malik P, et al.: Hypocalcemia and vitamin D deficiency amongst migraine patients: a nationwide retrospective study. Medicina. 2019, 55:407. 10.3390/medicina55080407

9. Latinovic R, Gulliford M, Ridsdale L: Headache and migraine in primary care: consultation, prescription, and referral rates in a large population. J Neurol Neurosurg Psychiatry. 2006, 77:385-387. 10.1136/jnnp.2005.073221

10. Stovner LJ, Hagen K, Jensen R, et al.: The global burden of headache: a documentation of headache prevalence and disability worldwide. Cephalalgia. 2007, 27:193-210. 10.1111/j.1468-2982.2007.01288.x

11. Steiner TJ, Stovner LJ, Vos T: GBD 2015: migraine is the third cause of disability in under 50s . J Headache Pain. 2016, 17:104. 10.1186/s10194-016-0699-5

12. Sites BD, Beach ML, Davis MA: Increases in the use of prescription opioid analgesics and the lack of improvement in disability metrics among users. Reg Anesth Pain Med. 2014, 39:6-12. 10.1097/aap.0000000000000022

13. Levin M: Opioids in headache. Headache. 2014, 54:12-21. 10.1111/head.12266

14. Buse DC, Manack A, Serrano D, Turkel C, Lipton RB: Sociodemographic and comorbidity profiles of chronic migraine and episodic migraine sufferers. J Neurol Neurosurg Psychiatry. 2010, 81:428-432. 10.1136/jnnp.2009.192492

15. Choong CK, Ford JH, Nyhuis AW, Joshi SG, Robinson RL, Aurora SK, Martinez JM: Clinical characteristics and treatment patterns among patients diagnosed with cluster headache in U.S. healthcare claims data. Headache. 2017, 57:1359-1374. 10.1111/head.13127

16. Saper JR, Lake AE, Bain PA, et al.: A practice guide for continuous opioid therapy for refractory daily headache: patient selection, physician requirements, and treatment monitoring. Headache. 2010, 50:11751193. 10.1111/j.1526-4610.2010.01733.x 


\section{Cureus}

17. Guidelines for the Chronic Use of Opioid Analgesics . (2017). Accessed: September 21, 2019: https://www.fsmb.org/siteassets/advocacy/policies/opioid_guidelines_as_adopted_april-2017_final.pdf.

18. Yarborough BJ, Stumbo SP, Janoff SL, et al.: Understanding opioid overdose characteristics involving prescription and illicit opioids: a mixed methods analysis. Drug Alcohol Depend. 2016, 167:49-56. 10.1016/j.drugalcdep.2016.07.024

19. Lembke A, Humphreys K, Newmark J: Weighing the risks and benefits of chronic opioid therapy . Am Fam Physician. 2016, 93:982-990.

20. McCormick PJ, Lin HM, Deiner SG, Levin MA: Validation of the All Patient Refined Diagnosis Related Group (APR-DRG) Risk of Mortality and Severity of Illness modifiers as a measure of perioperative risk. J Med Syst. 2018, 42:81. 10.1007/s10916-018-0936-3

21. Baram D, Daroowalla F, Garcia R, et al.: Use of the All Patient Refined-Diagnosis Related Group (APR-DRG) Risk of Mortality score as a severity adjustor in the medical ICU. Clin Med Circ Respirat Pulm Med. 2008, 2:19-25. 10.4137/ccrpm.s544 